\title{
Heart Transplant in Older Adults
}

\author{
Joshua A. Rushakoff ${ }^{1}$ Evan P. Kransdorf ${ }^{1}$ \\ Accepted: 2 December 2021 / Published online: 13 January 2022 \\ (C) The Author(s), under exclusive licence to Springer Nature Switzerland AG 2022
}

\begin{abstract}
Purpose of Review Older adults with end-stage heart failure may be candidates for heart transplantation (HT) and changing guidelines and institutional policies have increased the availability of HT for septuagenarians. This review explores historical, pre-HT evaluation, and post-HT outcomes for older adult HT recipients.

Recent Findings Rates of HT in older adults have increased in the past decade and more than 800 septuagenarians have undergone HT. Older adult HT recipients have similar survival, rehospitalization, and graft failure rates when compared to younger patients despite additional comorbidities and higher risk donors.

Summary HT is feasible in carefully selected older adults. As the number of older adults who are considered for HT increases, additional research into population-specific assessment tools will be needed. Furthermore, age-related immune changes warrant population-specific studies on immunosuppressive regimens.
\end{abstract}

Keywords Heart transplant · Geriatrics · Heart failure · Older adults · Frailty · Transplant outcomes · Graft failure

$\begin{array}{ll}\text { Abbreviations } \\ \text { CYP3A } & \text { Cytochrome p450 3A } \\ \text { DSA } & \text { Donor-specific antibodies } \\ \text { HF } & \text { Heart failure } \\ \text { HT } & \text { Heart transplant } \\ \text { ISHLT } & \text { International Society for Heart and Lung } \\ & \text { Transplantation } \\ \text { LVAD } & \text { Left ventricular assist device } \\ \text { MCS } & \text { Mechanical circulatory support } \\ \text { OPTN } & \text { Organ Procurement and Transplantation } \\ & \text { Network } \\ \text { PFP } & \text { Physical Frailty Phenotype } \\ \text { UNOS } & \text { United Network for Organ Sharing } \\ \text { US } & \text { United States }\end{array}$

This article is part of the Topical Collection on Frailty and Gerontology

Evan P. Kransdorf

evan.kransdorf@cshs.org

1 Smidt Heart Institute, Cedars-Sinai Medical Center, 8670

Wilshire Blvd, Suite 200, Beverly Hills, CA 90211, USA

\section{Introduction}

Heart failure (HF) is common among older adults in the United States (US). Recent data reveal that $7.5 \%$ of men and $3.9 \%$ of women between 60 and 79 years old have HF and $9.5 \%$ of men and $11 \%$ of women over 80 years old carry this diagnosis [1]. With the aging of the population, the prevalence of HF is expected to continue increasing in coming years $[1,2]$. The introduction of evidence-based medical and device therapies for heart failure over the past 30 years initially led to a significant decline in HF-related mortality. However, recent data show that HF-associated mortality is stable or up-trending across all regions of the US [3, 4]. Additionally, despite management improvements, HF remains a morbid diagnosis, especially for older patients and the 1-year mortality rate for Medicare beneficiaries with an incident HF diagnosis is $24.4 \%$.

The high HF burden and aging population has led to an increase in the number of older patients with end-stage disease refractory to medical therapy. Patients with end-stage HF may be candidates for left ventricular assist device (LVAD) implantation or heart transplantation (HT). LVAD use in patients over 75 years old has increased dramatically from $3.5 \%$ of all LVAD implantations in 2003 to $10.5 \%$ in 2014 [5]. Caraballo et al. reported age as an independent predictor of mortality following LVAD implantation suggesting this strategy may remain suboptimal [6]. More 
recently, Emerson et al. reported LVAD use in older patients are associated with improvements in functional capacity and quality of life [7]. HT has increasingly been considered for

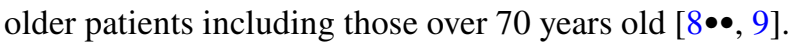

This review of HT in older adult patients explores the historical context, modern trends, peri-transplant management, and post-transplant outcomes for this important population.

\section{History of Heart Transplantation in Older Adults}

Following the introduction of cyclosporine in 1981 and monoclonal antibody OKT3 in 1983, solid organ transplantation rapidly expanded. HT morphed from a rare procedure (189 HTs in 1982), to increasingly common (2343 HTs in 1995). Quickly, organ scarcity became the limiting factor in the HT process heightening focus on recipient selection [10]. The United Network for Organ Sharing (UNOS), administrators of the Organ Procurement and Transplantation Network (OPTN), established absolute and relative contraindications to guide organ allocation. Initially, advanced age was considered a contraindication to HT [11]. Ethical considerations and concerns that multi-comorbid older adults may have worse outcomes following HT limited access for older adults. However, in the 1990s, single center studies emerged reporting that carefully selected older adult patients had similar post-transplant outcomes when compared to younger recipients [11-16]. With these HT successes, individual transplant programs began to view the upper age limit for candidate consideration with increasing flexibility, and by $2002,10 \%$ of HT recipients were over 65 years old. In 2006, the International Society for Heart and Lung Transplantation (ISHLT) published updated listing criteria for HT which specified that patients up to 70 years of age should be considered for HT (class I recommendation) and carefully selected patients over 70 years of age could be considered for HT (class IIb recommendation) [17].
Since the publication of the revised ISHLT listing criteria, the proportion of older adult patients newly listed for HT has increased. At the end of 2019, $16.4 \%$ of patients on the HT waiting list were over 65 years old $[18,19]$. The proportion of new listings of candidates over 70 years of age has grown dramatically from $2.5 \%$ in 2000 to $11 \%$ in 2017 [8••]. The increased listing of older adult candidates has led to a corresponding increase in the heart transplant rate for these candidates. Following a nadir in 2015 for HTs in the US, there has been a rise in the rate of HT across all age groups. This trend is most pronounced in patients over 65 years old who went from a HT rate of 74.3 per 100 waitlist years in 2015 to 132.2 in 2019. Similarly, recipients over 65 years old increased from $12.9 \%$ of adult HT in 2007 to $19.3 \%$ in 2019 (Fig. 1) [18]. Between 2000 and 2018, 1203 (2.1\%) transplants were performed in septuagenarians $[8 \bullet \bullet]$.

The impact of the coronavirus-19 (COVID-19) pandemic on these trends is yet to be determined. Initial reports suggest that the COVID-19 pandemic has had a profound effect on solid organ transplantation in the US. During the early stages of the pandemic (January-May 2020), there was a $75 \%$ increase in HT waitlist inactivations with a $26 \%$ decrease in HT volume [21]. A subsequent analysis of the first 9 months of the COVID-19 pandemic (January-September 2020) revealed a $43 \%$ decrease in HT nationally [22]. Additional research is needed to understand the implications of increased waitlist inactivations and decreased national HT volume on older adult HT candidates.

\section{Pre-transplant Considerations for Older Adults}

The pre-transplant evaluation of older HT candidates should differ from that performed for younger patients (Fig. 2). Older patients often have a greater number of comorbidities which must be considered. For HT candidates added to the waitlist between 2000 and 2018, a higher percentage of septuagenarians had hypertension (55.6\%), prior malignancy
Fig. 1 Heart transplant rates by candidate age. Figure used with permission from John Wiley and Sons. Originally published by Colvin et al., [20]

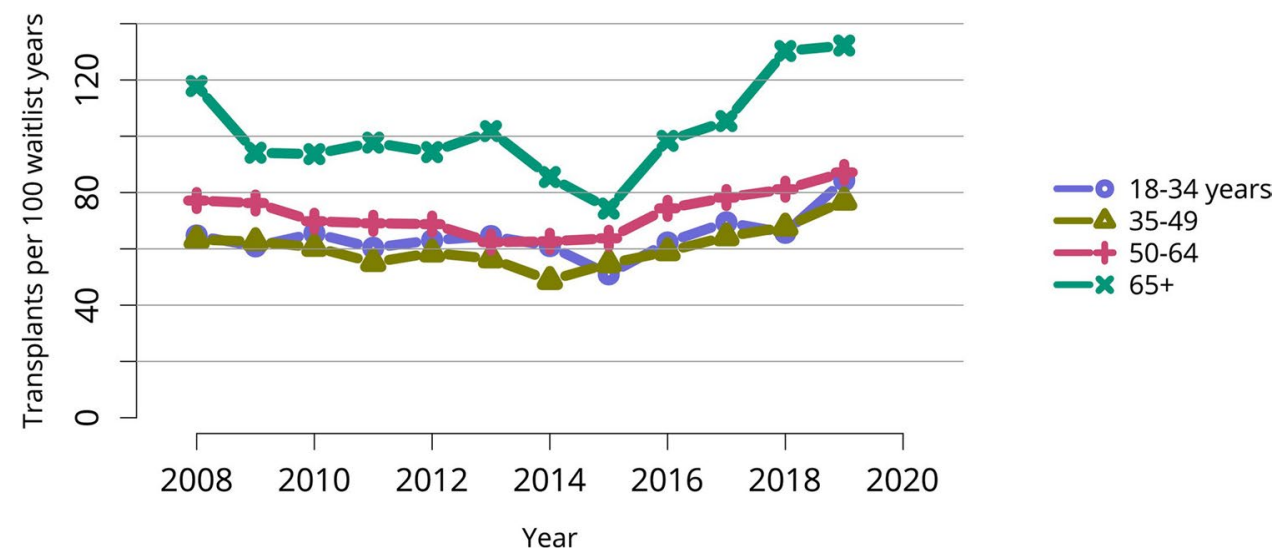


Fig. 2 Summary of heart transplantation considerations in older adults

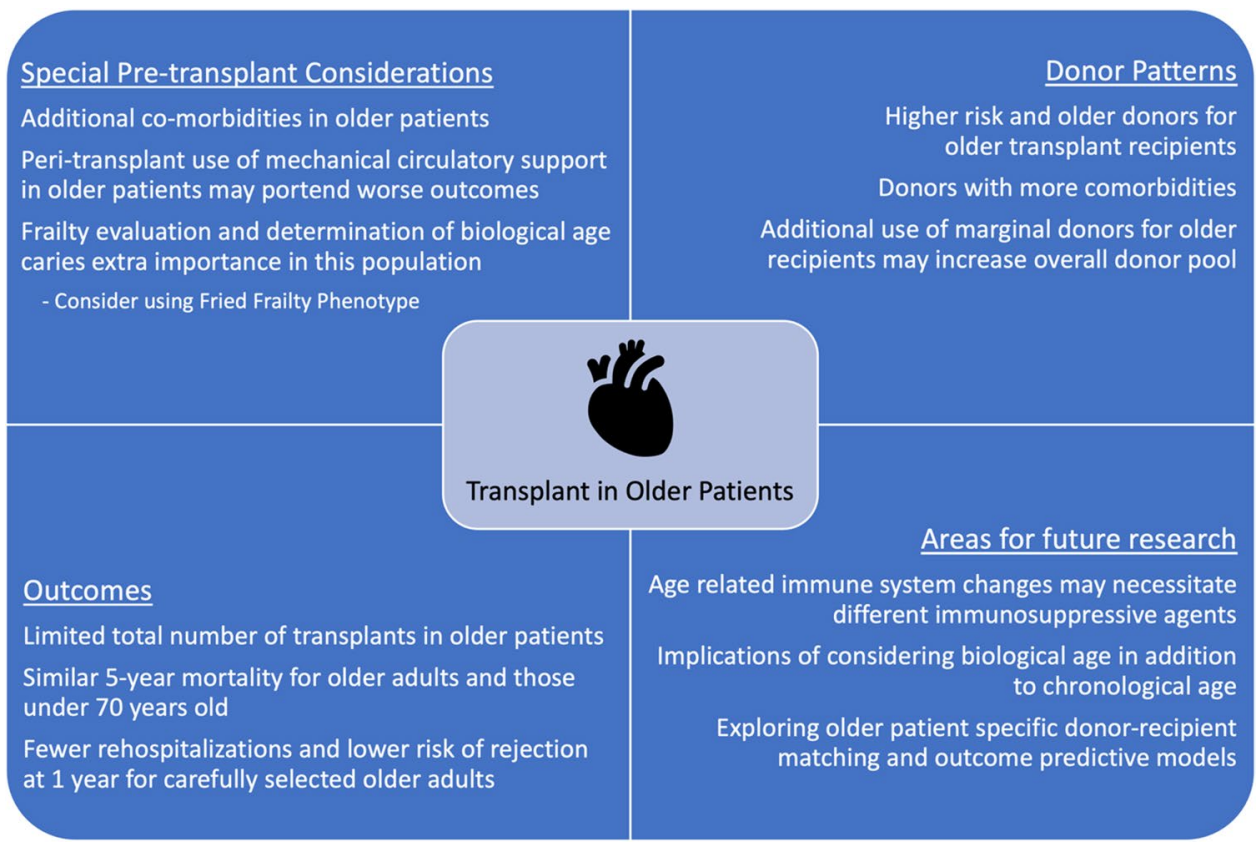

(11.2\%), and chronic kidney disease (mean creatinine clearance $56.9 \mathrm{ml} / \mathrm{min}$ ) compared to candidates under 70 years old $(48.6 \%, 6.6 \%$, and $78.8 \mathrm{ml} / \mathrm{min}$, respectively) [8••]. There were no significant differences in rates of diabetes, peripheral arterial disease (PAD), or chronic obstructive pulmonary disease (COPD) between the groups. While creatinine clearance was significantly lower for candidates over 70 years old, prior dialysis was less frequent. These characteristics largely mirror those reported in previous analyses of HT candidates over 70 years of age [23]. In addition to comorbidities, providers should evaluate cognitive function, psychosocial support, goals of care, and caregiver support [24, 25••].

Cooper et al. and Jaiswal et. al. both reported that HT recipients over 70 years old were less acutely ill at the time

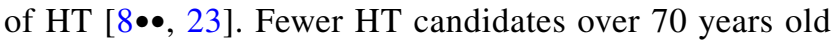
required extracorporeal membrane oxygenation or intraaortic balloon pump at the time of listing for transplant. Interestingly, while a higher percentage of older patients added to the waitlist had a history of LVAD compared to younger patients, fewer older transplant recipients had a history of LVAD. The discrepancy likely reflects the known decreased survival for patients over 70 years old following LVAD implantation. Despite a lower percentage of patients requiring in hospital MCS, patients over 70 years old have a much shorter median time on the waitlist (46 days) compared to younger candidates (103 days).

A special consideration for older HT candidates is frailty. Frailty is a clinically recognizable state of decreased physiologic reserve resulting in a limited ability to cope with stressors. Its prevalence increases with age and impacts $7-12 \%$ of US adults over 65 years old [26-29]. Biological age, which reflects a patient's frailty, has been shown to be more closely associated with mortality than chronological age [30, 31]. Age-independent frailty is especially relevant in older HT candidates who face the significant physiologic stressor of transplant. However, frailty assessment is complicated by the lack of standardized assessments and, in HT candidates, the overlap between the effects of end-stage heart disease and the effects of frailty on physical functioning. Scoring systems have emerged to systematically characterize frailty such as the Physical Frailty Phenotype (PFP), developed by Dr. Fried and colleagues, and the Short Physical Performance Battery (SPPB). Of these, the Frailty Heart Group recommended a modified PFP [32] in HT evaluation as it is easy to perform and has been validated in patients with advanced HF [26, 33]. While evidence remains sparse, observational studies have shown frailty can be incorporated into the HT evaluation process and is an independent risk factor for mortality and prolonged hospitalization following HT [34, 35••, 36]. Evidence from the kidney transplant literature reflects similar adverse short- and long-term posttransplant outcomes for frail candidates [27, 37-39]. As the evidence for frailty in HT candidates remains limited and assessment remains challenging, frailty has not yet formally been added to HT listing guidelines at this time.

A final consideration during the pre-transplant period is the donor. Donor organs remain scarce and HT waitlist mortality remains significant [40]. This organ scarcity and ethical concerns about allocating organs to older recipients is reflected in the 2016 ISHLT Listing Criteria for HT which specify that for carefully selected patients over 70 years of age who are considered for HT, an alternate-type program be considered [25]. Analyses of donors for patients over 
70 years of age reflect these recommendations. Donors for older patients have been older themselves, 36 years old compared to 30 years old for younger patients, with more comorbidities (diabetes mellitus $5.1 \%$ vs $3.0 \%$, hypertension

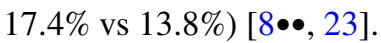

The data from the past two decades reflects programs' hesitation in considering sicker older adult transplant candidates. For example, while COPD and PVD prevalence increase with age in the general population [41, 42], the percentage of candidates over 70 years old added to the waitlist with these conditions was lower compared to younger patients. Similarly, the much lower rate of dialysis in older candidates $(0.8 \%)$ compared to younger patients $(2.7 \%)[8 \bullet \bullet]$ suggests that despite a lower median creatinine clearance few older candidates had advanced, end stage renal dysfunction. More septuagenarians wait at home, highlighting careful recipient selection strategies and less acute illness prior to transplant. Finally, while older HT candidates have a lower risk profile than younger candidates, donor hearts for this population are higher risk.

\section{Heart Transplant Outcomes in Older Adults}

Two cohort studies have evaluated HT outcomes in septuagenarians (Table 1). First, Cooper et al. analyzed patients between January 1987 and March 2014 [23]. This cohort of 50,432 US HT patients included 715 patients over 70 years old. Next, Jaiswal et al. identified US HT candidates between January 2000 and August 2018 [8••]. This cohort included 37,155 HT recipients, of whom 806 were over 70 years old.

Table 1 Demographics and transplant outcomes in older adults

\begin{tabular}{llll}
\hline & Patients $>70$ & Patients 18-69 & \\
\hline $\begin{array}{l}\text { Number of patients } \\
\text { Outcomes }\end{array}$ & 806 & 36,329 & \\
Overall incident mortality & & & \\
$\quad 1$ year & $11.5 \%$ & $10.4 \%$ & \\
$\quad 5$ years & $20.4 \%$ & $19.2 \%$ & \\
Stroke incidence & $3.5 \%$ & $2.5 \%$ & $p=0.09$ \\
Graft failure & $1.5 \%$ & $1.8 \%$ & $p=0.46$ \\
Demographics & & & \\
Ischemic cardiomyopathy & $52.1 \%$ & $34.3 \%$ & $<0.01$ \\
Prior cardiac surgery & $49.4 \%$ & $39.7 \%$ & $<0.01$ \\
History of hypertension & $57.0 \%$ & $48.2 \%$ & $<0.01$ \\
History of any malignancy & $11.7 \%$ & $6.8 \%$ & $<0.01$ \\
Creatinine & 1.3 & 1.2 & $<0.01$ \\
History of dialysis & $0.1 \%$ & $2.1 \%$ & $<0.01$ \\
\hline
\end{tabular}

Table created with permission from John Wiley and Sons. Data originally published by Jaiswal et al
Both retrospective studies used OPTN data, introducing crossover between the two cohorts.

Cooper et al. reported increased adjusted 5-year mortality for patients over 70 years old both compared to the 18-59-year-old group (HR $1.35, p<0.001$ ) and to 60-69-year-old group (HR 1.20, $p=0.02$ ). However, when they excluded transplants before 2004, they showed no difference in adjusted 5-year mortality for patients over 70 years old compared to the 60-69-year-old group (HR $1.13, p=0.28$ ) [23]. Length of stay was comparable across age groups and patients over 70 years old had fewer rehospitalizations within 1 year of HT. The decreased rate of rehospitalization may reflect the lower risk of rejection for older HT recipients and the careful selection of healthier HT candidates. More patients over 70 years old had a stroke within 1 year of HT (2.4\%) compared to the 60-69-year-old (1.1\%) or $18-59$-year-old (1.0\%) groups.

The more recent cohort studied by Jaiswal et al. similarly showed no difference in adjusted 5-year mortality for HT recipients over 70 years old compared to younger recipients (HR 1.06, $p=0.43$ ) [8••]. The unadjusted 1-year and 5-year mortality for patients over 70 years old, $11.5 \%$ and $20.4 \%$, respectively, was higher than younger HT recipients. Like the previous study, incidence of stroke was higher in the older cohort.

Despite older donors with additional comorbidities, these two studies demonstrate that patients over 70 years of age have similar post-HT outcomes when compared to younger patients.

\section{Post-transplant Considerations for Older Adults}

HT recipients over 70 years old experience fewer rejection

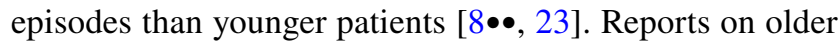
kidney transplant recipients mirror this pattern of decrease rates of rejection [43-45]. While rates of rejection are lower in older solid organ recipients, there is an increased risk for infection or malignancy in this population [46-48]. This risk profile suggests that post-transplant management could be tailored to the older adult to balance the risks of rejection with those of infection or malignancy.

There are numerous known age-related changes in immune system function. These age-related alterations in the immune system, important to consider in the post-transplant patient, are characterized by dysfunctional immune responses and termed immunosenescence [49]. T cell immunosenescence leads to reductions in differentiation and circulation of $\mathrm{T}$ cells and decreases in naïve $\mathrm{T}$ cells and $\mathrm{T}$ cell receptor diversity $[44,50]$. Furthermore, thymic involution is a hallmark of $\mathrm{T}$ cell immunosenescence [51]. Adjunct immune functions are similarly altered with aging including 
loss of the costimulatory CD28 molecule and abnormal production of pro-inflammatory cytokines [43]. The decline in $\mathrm{T}$ cell diversity limits older adults' ability to recognize foreign antigens and pathogens; however, this altered response may also explain the reduced risk of acute cellular rejection following transplant. Immune system changes impact humoral responses as well [44]. With aging, the B cell repertoire is skewed towards memory responses and there is a reduction in the volume of progenitor $B$ cells $[43,52]$. Though there is a paucity of studies on B cell immunosenescence and solid organ transplant, some evidence suggests a decrease in donor-specific antibodies (DSA) with increasing recipient age. Decreased DSA formation could be due to reduced humoral immune reactivity $[44,53]$. While older patients may form fewer DSAs, decreased humoral response leaves patients at increased risk of malignancy and infection.

Another consideration is the choice of immunosuppressive agents in older adult patients. There are no formal trials comparing post-HT immunosuppression regimens in older patients and furthermore older patients were often specifically excluded from clinical trials [43]. Providers should be aware of age-related physiologic changes which may impact immunosuppressant pharmacokinetics. For example, calcineurin inhibitors are metabolized by the cytochrome P450 3A subfamily (CYP3A) in the liver. However, studies of liver samples have shown significant declines in CYP3A activity with aging, and a prospective study of kidney transplant recipients showed that calcineurin inhibitor (tacrolimus and cyclosporine) trough levels are 50\% higher in recipients over 65 years of age [54]. Similarly, the active metabolite of mycophenolate mofetil, mycophenolic acid, reversibly binds to serum albumin. Age-associated changes in albumin can result in increased clearance of the unbound, active metabolite $[55,56]$.

Older transplant recipients have a different post-HT risk profile when compared to younger peers [57]. While the risk of rejection is lower in these patients, there are elevated risks of malignancy and infectious complications. Immunosenescence suggests that older solid organ transplant recipients may benefit from an individually tailored immunosuppression regimen. As the number of transplants in older candidates continues to increase, additional research is needed to clarify optimal immunosuppression strategies for this population following transplant.

\section{Conclusion}

HT in older adults is feasible and, in carefully selected patients, outcomes appear comparable to that in younger HT recipients. As the mean age continues to increase in the US population, an increasing number of older patients will require evaluation for advanced therapies. The HT evaluation process for this population should include the same steps as that for younger patients with additional consideration of determining biological age. Frailty evaluation may play an important role in this patient population. For those candidates who receive a HT, there is an observed decreased risk of rejection but increased risk of malignancy and infection in the post-transplant period. These outcomes in the context of immunosenescence and altered immunosuppressant pharmacokinetics suggest additional research is needed to optimize post-HT care for older adult patients.

\section{Declarations}

Conflict of Interest The authors declare no competing interests.

Human and Animal Rights and Informed Consent This article does not contain any studies with human or animal subjects performed by any of the authors.

\section{References}

Papers of particular interest, published recently, have been highlighted as: $\bullet$ Of major importance

1. Virani SS, Alonso A, Aparicio HJ, et al. Heart disease and stroke statistics-2021 update: a report from the American Heart Association. Circulation. 2021;143(8):e254-743. https://doi.org/10. 1161/CIR.0000000000000950.

2. Huffman MD, Berry JD, Ning H, et al. Lifetime risk for heart failure among white and black Americans: cardiovascular lifetime risk pooling project. J Am Coll Cardiol. 2013;61(14):1510 7. https://doi.org/10.1016/j.jacc.2013.01.022.

3. Glynn PA, Molsberry R, Harrington K, et al. Geographic variation in trends and disparities in heart failure mortality in the United States, 1999 to 2017. J Am Heart Assoc. 2021;10(9): e020541. https://doi.org/10.1161/JAHA.120.020541.

4. Vasan RS, Zuo Y, Kalesan B. Divergent temporal trends in morbidity and mortality related to heart failure and atrial fibrillation: age, sex, race, and geographic differences in the United States, 1991-2015. J Am Heart Assoc. 2019;8(8): e010756. https://doi. org/10.1161/JAHA.118.010756.

5. Rali AS, Vuddanda V, Masoomi R, et al. Trends in LVADs in the geriatric population: demographics for 2003-2014. J Card Fail. 2017;23(8):S17. https://doi.org/10.1016/j.cardfail.2017.07.059.

6. Caraballo C, DeFilippis EM, Nakagawa S, et al. Clinical outcomes after left ventricular assist device implantation in older adults: an INTERMACS analysis. JACC Heart Fail. 2019;7(12):1069-78. https://doi.org/10.1016/j.jchf.2019.10.004.

7. Emerson D, Chikwe J, Catarino P, et al. Contemporary left ventricular assist device outcomes in an aging population. J Am Coll Cardiol. 2021;78(9):883-94. https://doi.org/10.1016/j.jacc.2021. 06.035 .

8.• Jaiswal A, Gadela NV, Baran D, et al. Clinical outcomes of older adults listed for heart transplantation in the United States. J Am Geriatr Soc. Published online June 8, 2021. https://doi.org/10. 1111 /jgs.17271. This study presents UNOS data on heart transplant in older adults including demographics, donor 
information, and post-HT outcomes. Older adults are compared to their younger peers.

9. Yusen RD, Edwards LB, Dipchand AI, et al. The registry of the International Society for Heart and Lung Transplantation: thirty-third adult lung and heart-lung transplant report-2016; focus theme: primary diagnostic indications for transplant. J Heart Lung Transplant Off Publ Int Soc Heart Transplant. 2016;35(10):1170-84. https://doi.org/10.1016/j.healun.2016. 09.001 .

10. Port FK, Merion RM, Finley MP, Goodrich NP, Wolfe RA. Trends in organ donation and transplantation in the United States, 1996-2005. Am J Transplant. 2007;7(s1):1319-26. https://doi.org/10.1111/j.1600-6143.2007.01778.x.

11. Daneshvar DA, Czer LSC, Phan A, Trento A, Schwarz ER. Heart transplantation in the elderly: why cardiac transplantation does not need to be limited to younger patients but can be safely performed in patients above 65 years of age. Ann Transplant. 2010;15(4):110-9.

12. Marelli D, Laks H, Kobashigawa JA, et al. Seventeen-year experience with 1,083 heart transplants at a single institution. Ann Thorac Surg. 2002;74(5):1558-66. https://doi.org/10.1016/ s0003-4975(02)03933-4 (discussion 1567).

13. John R, Rajasinghe HA, Chen JM, et al. Long-term outcomes after cardiac transplantation: an experience based on different eras of immunosuppressive therapy. Ann Thorac Surg. 2001;72(2):440-9. https://doi.org/10.1016/S0003-4975(01) 02784-9.

14. Borkon AM, Muehlebach GF, Jones PG, et al. An analysis of the effect of age on survival after heart transplant. J Heart Lung Transplant Off Publ Int Soc Heart Transplant. 1999;18(7):66874. https://doi.org/10.1016/s1053-2498(99)00024-8.

15. Defraigne JO, Demoulin JC, Beaujean MA, Delbouille MH, Meurisse M, Limet R. Cardiac transplantation beyond 55 years of age. Transpl Int Off J Eur Soc Organ Transplant. 1990;3(2):59-61. https://doi.org/10.1007/BF00336203.

16. Morgan JA, John R, Mancini DM, Edwards NM. Should heart transplantation be considered as a treatment option for patients aged 70 years and older? J Thorac Cardiovasc Surg. 2004;127(6):1817-9. https://doi.org/10.1016/j.jtcvs.2003.12. 035 .

17. Mehra MR, Kobashigawa J, Starling R, et al. Listing criteria for heart transplantation: International Society for Heart and Lung Transplantation guidelines for the care of cardiac transplant candidates-2006. J Heart Lung Transplant Off Publ Int Soc Heart Transplant. 2006;25(9):1024-42. https://doi.org/10. 1016/j.healun.2006.06.008.

18. Colvin M, Smith JM, Ahn Y, et al. OPTN/SRTR 2019 annual data report: heart. Am J Transplant Off J Am Soc Transplant Am Soc Transpl Surg. 2021;21(Suppl 2):356-440. https://doi.org/10. 1111/ajt.16492.

19. Colvin M, Smith JM, Hadley N, et al. OPTN/SRTR 2017 annual data report: heart. Am J Transplant. 2019;19(S2):323-403. https://doi.org/10.1111/ajt.15278.

20. Colvin M, Smith JM, Ahn Y, et al. OPTN/SRTR 2019 Annual Data Report: Heart. American Journal of Transplantation. 2021;21(S2):356-440. https://doi.org/10.1111/ajt.16492.

21. DeFilippis EM, Sinnenberg L, Reza N, et al. Trends in US heart transplant waitlist activity and volume during the coronavirus disease 2019 (COVID-19) pandemic. JAMA Cardiol. 2020;5(9):1048. https://doi.org/10.1001/jamacardio.2020.2696.

22. Goff RR, Wilk AR, Toll AE, McBride MA, Klassen DK. Navigating the COVID-19 pandemic: Initial impacts and responses of the Organ Procurement and Transplantation Network in the United States. Am J Transplant Off J Am Soc Transplant Am Soc Transpl Surg. 2021;21(6):2100-12. https://doi.org/10. 1111/ajt.16411.
23. Cooper LB, Lu D, Mentz RJ, et al. Cardiac transplantation for older patients: characteristics and outcomes in the septuagenarian population. J Heart Lung Transplant Off Publ Int Soc Heart Transplant. 2016;35(3):362-9. https://doi.org/10.1016/j. healun.2015.10.028.

24. Lee SJ, Kim KH, Hong SK, Hankins S. Evaluation of a heart transplant candidate. Curr Cardiol Rep. 2017;19(12):133. https://doi.org/10.1007/s11886-017-0934-y.

25. Mehra MR, Canter CE, Hannan MM, et al. The 2016 International Society for Heart Lung Transplantation listing criteria for heart transplantation: a 10-year update. J Heart Lung Transplant Off Publ Int Soc Heart Transplant. 2016;35(1):1-23.https:// doi.org/10.1016/j.healun.2015.10.023. These updated heart transplantlisting guidelines provide important changes to thosepublished 10 years earlier. The listing guidelines further theopportunities for transplant in older adult.

26. Kobashigawa J, Shah P, Joseph S, et al. Frailty in heart transplantation: report from the heart workgroup of a consensus conference on frailty. Am J Transplant Off J Am Soc Transplant Am Soc Transpl Surg. 2021;21(2):636-44. https://doi.org/10.1111/ ajt.16207.

27. Cheng XS, Lentine KL, Koraishy FM, Myers J, Tan JC. Implications of frailty for peritransplant outcomes in kidney transplant recipients. Curr Transplant Rep. 2019;6(1):16-25. https://doi. org/10.1007/s40472-019-0227-z.

28. Clegg A, Young J, Iliffe S, Rikkert MO, Rockwood K. Frailty in elderly people. The Lancet. 2013;381(9868):752-62. https:// doi.org/10.1016/S0140-6736(12)62167-9.

29. Xue Q-L. The frailty syndrome: definition and natural history. Clin Geriatr Med. 2011;27(1):1-15. https://doi.org/10.1016/j. cger.2010.08.009.

30. Graham JE, Mitnitski AB, Mogilner AJ, Rockwood K. Dynamics of cognitive aging: distinguishing functional age and disease from chronologic age in a population. Am J Epidemiol. 1999;150(10):1045-54. https://doi.org/10.1093/oxfordjournals. aje.a009928.

31. Mitnitski AB, Graham JE, Mogilner AJ, Rockwood K. Frailty, fitness and late-life mortality in relation to chronological and biological age. BMC Geriatr. 2002;2(1):1. https://doi.org/10. 1186/1471-2318-2-1.

32. Lp F, Cm T, Walston J, et al. Frailty in older adults: evidence for a phenotype. J Gerontol A Biol Sci Med Sci. 2001;56(3):M14656. https://doi.org/10.1093/gerona/56.3.m146.

33. Afilalo J, Alexander KP, Mack MJ, et al. Frailty assessment in the cardiovascular care of older adults. J Am Coll Cardiol. 2014;63(8):747-62. https://doi.org/10.1016/j.jacc.2013.09.070.

34. Jha S, Newton P, Montgomery E, et al. Frailty predicts mortality after heart transplantation. Transplantation. 2018;102:S62. https://doi.org/10.1097/01.tp.0000542634.50135.0e.

35.• Macdonald PS, Gorrie N, Brennan X, et al. The impact of frailty on mortality after heart transplantation. J Heart Lung Transplant. 2021;40(2):87-94. https://doi.org/10.1016/j.healun.2020.11.007. This recent study highlights the importance of determining biologic age and incorporating frailty assessments into the pre-transplant evaluation process.

36. Goldwater D, Ventigan N, Shih L, et al. Feasibility of incorporating frailty testing into standard assessment of heart transplant candidacy. J Heart Lung Transplant. 2020;39(4, Supplement):S154. https://doi.org/10.1016/j.healun.2020.01. 1094.

37. McAdams-DeMarco MA, Ying H, Olorundare I, et al. Individual frailty components and mortality in kidney transplant recipients. Transplantation. 2017;101(9):2126-32. https://doi.org/10.1097/ TP.0000000000001546.

38. McAdams-DeMarco MA, Law A, Salter ML, et al. Frailty and early hospital readmission after kidney transplantation. Am 
J Transplant Off J Am Soc Transplant Am Soc Transpl Surg. 2013;13(8):2091-5. https://doi.org/10.1111/ajt.12300.

39. Exterkate L, Slegtenhorst BR, Kelm M, et al. Frailty and transplantation. Transplantation. 2016;100(4):727-33. https://doi.org/ 10.1097/TP.0000000000001003.

40. Bakhtiyar SS, Godfrey EL, Ahmed S, et al. Survival on the heart transplant waiting list. JAMA Cardiol. 2020;5(11):1227-35. https://doi.org/10.1001/jamacardio.2020.2795.

41. CDC - Data and statistics - chronic obstructive pulmonary disease (COPD). Published June 14, 2021. Accessed August 2, 2021. https://www.cdc.gov/copd/data.html

42. CDC. Peripheral arterial disease (PAD) I cdc.gov. Centers for Disease Control and Prevention. Published September 8, 2020. Accessed August 2, 2021. https://www.cdc.gov/heartdisease/ PAD.htm

43. Krenzien F, ElKhal A, Quante M, et al. A rationale for ageadapted immunosuppression in organ transplantation. Transplantation. 2015;99(11):2258-68. https://doi.org/10.1097/TP.00000 00000000842.

44. Cheungpasitporn W, Lentine KL, Tan JC, et al. Immunosuppression considerations for older kidney transplant recipients. Curr Transplant Rep. 2021;8(2):100-10. https://doi.org/10.1007/ s40472-021-00321-6.

45. Peeters LEJ, Andrews LM, Hesselink DA, de Winter BCM, van Gelder T. Personalized immunosuppression in elderly renal transplant recipients. Pharmacol Res. 2018;130:303-7. https:// doi.org/10.1016/j.phrs.2018.02.031.

46. Lemoine M, Beauport DT, Lobbedez T, et al. Risk factors for early graft failure and death after kidney transplantation in recipients older than 70 years. Kidney Int Rep. 2019;4(5):656-66. https://doi.org/10.1016/j.ekir.2019.01.014.

47. Tessari G, Naldi L, Boschiero L, et al. Incidence of primary and second cancers in renal transplant recipients: a multicenter cohort study. Am J Transplant Off J Am Soc Transplant Am Soc Transpl Surg. 2013;13(1):214-21. https://doi.org/10.1111/j. 1600-6143.2012.04294.x.

48. Saxena R, Yu X, Giraldo M, et al. Renal transplantation in the elderly. Int Urol Nephrol. 2009;41(1):195-210. https://doi.org/ 10.1007/s11255-008-9489-6.

49. Heinbokel T, Elkhal A, Liu G, Edtinger K, Tullius SG. Immunosenescence and organ transplantation. Transplant Rev Orlando Fla. 2013;27(3):65-75. https://doi.org/10.1016/j.trre.2013.03. 001 .
50. Naylor K, Li G, Vallejo AN, et al. The influence of age on T cell generation and TCR diversity. J Immunol Baltim Md 1950. 2005;174(11):7446-52. https://doi.org/10.4049/jimmunol.174. 11.7446 .

51. Hirokawa K, Makinodan T. Thymic involution: effect on T cell differentiation. J Immunol Baltim Md 1950. 1975;114(6):1659-64.

52. Frasca D, Diaz A, Romero M, Landin AM, Blomberg BB. Age effects on B cells and humoral immunity in humans. Ageing Res Rev. 2011;10(3):330-5. https://doi.org/10.1016/j.arr.2010. 08.004 .

53. Sellarés J, de Freitas DG, Mengel M, et al. Understanding the causes of kidney transplant failure: the dominant role of antibody-mediated rejection and nonadherence. Am J Transplant Off J Am Soc Transplant Am Soc Transpl Surg. 2012;12(2):388-99. https://doi.org/10.1111/j.1600-6143.2011.03840.x.

54. Jacobson PA, Schladt D, Oetting WS, et al. Lower calcineurin inhibitor doses in older compared to younger kidney transplant recipients yield similar troughs. Am J Transplant Off J Am Soc Transplant Am Soc Transpl Surg. 2012;12(12):3326-36. https:// doi.org/10.1111/j.1600-6143.2012.04232.x.

55. McLean AJ, Le Couteur DG. Aging biology and geriatric clinical pharmacology. Pharmacol Rev. 2004;56(2):163-84. https://doi. org/10.1124/pr.56.2.4.

56. van Hest RM, Mathot RAA, Pescovitz MD, Gordon R, Mamelok $\mathrm{RD}$, van Gelder T. Explaining variability in mycophenolic acid exposure to optimize mycophenolate mofetil dosing: a population pharmacokinetic meta-analysis of mycophenolic acid in renal transplant recipients. J Am Soc Nephrol JASN. 2006;17(3):871-80. https://doi.org/10.1681/ASN.2005101070.

57. Wever-Pinzon O, Edwards LB, Taylor DO, et al. Association of recipient age and causes of heart transplant mortality: Implications for personalization of post-transplant management-an analysis of the International Society for Heart and Lung Transplantation Registry. J Heart Lung Transplant Off Publ Int Soc Heart Transplant. 2017;36(4):407-17. https://doi.org/10.1016/j. healun.2016.08.008.

Publisher's Note Springer Nature remains neutral with regard to jurisdictional claims in published maps and institutional affiliations. 